\title{
Therapeutic Effects of Black Tea on Micronuclei (Oral Cancer Biomarker) Induced by Betel Quid: A Mini Review
}

Aniket Adhikari*

ISSN: 2637-773X

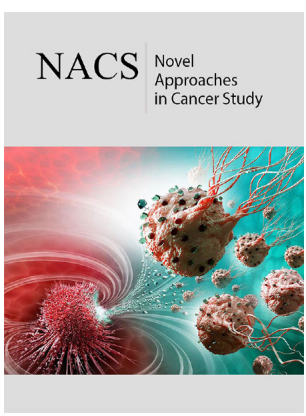

*Corresponding author: Aniket Adhikari, Department of Genetics, 99, Sarat Bose Road. Kolkata - 700026, India

Submission: 贈 : November 17, 2020

Published: 眥 December 15, 2020

Volume 5 - Issue 4

How to cite this article: Aniket Adhikari*. Therapeutic Effects of Black Tea on Micronuclei (Oral Cancer Biomarker) Induced by Betel Quid: A Mini Review. Nov Appro in Can Study. 5(4). NACS.000620. 2020. DOI: 10.31031/NACS.2020.05.000620

Copyright@Aniket Adhikari*, This article is distributed under the terms of the Creative Commons Attribution 4.0 International License, which permits unrestricted use and redistribution provided that the original author and source are credited.

\section{Introduction}

Department of Genetics, India

\begin{abstract}
Tea, a national drink has been used in India and various parts of the world for many centuries for its beneficial action in the human body. Consumption of black tea (due to its chemo preventive property) has been shown to exert a protective effect against oral squamous cell carcinoma. Micronuclei (MN) formation has been observed in cancer and pre-cancerous lesions of the oral cavity of betel quid chewers which also known as cancer biomarker. The present review focuses on therapeutic effects of black tea on micronuclei associated with betel quid chewers.
\end{abstract}

Keywords: Black tea; Micronuclei (MN); Betel quid (BQ); Oral squamous cell carcinoma (OSCC)

Tea considered as a mental stimulant, mood elevator and also advocated for oral cancer, is a national drink has been used in India. Consumption of black tea for the chemo preventive action has been shown to exert a protective effect against oral cancer [1]. The major polyphenol components of black tea (the fermented product) are theaflavins (1-3\% dry weight) and thearubigins (10-40\% dry weight). A study suggests that black-tea derived polyphenols also showed one of the chemo-preventive properties shown by green tea polyphenols.

It was reported that drinking black tea has benefits equal to those of drinking green tea in terms of their antioxidant capacities because theaflavins present in black tea possess at least the same antioxidant potency as catechins present in green tea [2]. It is reported that a group of theaflavins (TF) in black tea, specifically theaflavin-3, 3-digallate (TF3), has strong antioxidant activity similar to (-)-epigallocatechin gallate (EGCG), a major antioxidant in green tea $[3,4]$. Freshly harvested tea leafs are processed differently in different parts of the world to give oolong tea (2\%), green tea (20\%) or black tea (78\%) [5].

Micronuclei (MN) are small extra nuclei formed in the epithelial cell during metaphase and anaphase stage of cell division and also as an oral cancer biomarker [6]. Oral squamous cell carcinoma (OSCC) and the most common oral pre malignancies such as leukoplakia and oral sub mucous fibrosis appear to be related to the habit of betel quid (BQ) chewing in India and also South East Asian countries. Areca nut (Areca catechu) a major component of BQ, contains certain alkaloid that give rise to nitrosamines [7]. Genetic defects of the CYP2A6 gene and also individual effects of $\mathrm{BQ}$ ingredients trigger the CYP2A6 gene related to a cause cancer of oral cavity.

\section{Conclusion}

In our study, after supplementation of black tea for 6 months we have screened the percentage of micronuclei are reduced in 4 folds and the area of white patches (leukoplakia) was reduced in size. The antioxidant properties of tea play a vital role to reduce the cancer biomarker (MN). The polyphenolic component of tea decreases its antioxidant property with the combination of milk. So black tea i.e., tea without milk plays an important role for scavenging the free radicals and promote good oral hygiene. 


\section{Conflicts of Interest}

There is no conflict of interest to declare.

\section{References}

1 Nelson DR, Koymans L, Kaamataki T, Stageman JJ, Feyereisen R, et al. (1996) P450 super family: Update on new sequences, gene mapping, accession numbers and nomencleture. Pharmacogenetics 6(1): 1- 42 .

2 Leung LK, Su Y, Chen R, Zang Z, Huang Y, et al. (2001) Theaflavins in black and catechins in green tea are equally effective antioxidants. J Nutr 131(9): 2248-2251.

3 Yoshida H, Ishikawa T, Hosoai H, Suzukawa M, Ayaori M, et al. (1999) Inhibitory effect of tea flavonoids on the ability of cells to oxidize low density lipoprotein. Biochem Pharmacol 58(11): 1695-1703.
4 Lin YL, Tsai SH, Lin-Shiau SY, Ho CT, Lin JK (1999) Theaflavin-3, 3'-digallate from black tea blocks the nitric oxide synthase by down regulating the activation of NF-_kappaB in macrophages. Eur J Pharmacol 367(2-3): 379-388.

5 Kuroda Y, Hara Y (1999) Antimutagenic and anticarcinogenic activity of tea polyphenols. Mutat Res 436(1): 69-97.

6 Talukder G, Sharma A (2004) Tea as a protectant in human cancer National Tea Research Foundation.

7 Hoffmann D, Brunnemann KD, Prokopczyk B, Djordjevic MV (1994) Tobacco-specific $\mathrm{N}$-nitrosamines and areca-derived $\mathrm{N}$-nitrosamines: Chemistry, biochemistry, carcinogenicity, and relevance to humans. J Toxicol Environ Health 41(1): 1-52. 